\title{
Mass exchange evaluation during optimization of osmotic dehydration for Oyster mushrooms (Pleurotus sajor-caju) in salt-sugar solution
}

\author{
H. G. Ramya*, Satish Kumar and Mahesh Kumar
}

Department of Processing and Food Engineering, COAE\&T, Punjab Agricultural University, Ludhiana (Punjab), INDIA

*Corresponding author. E-mail: ramyarinda@gmail.com

Received: February 28, 2014; Revised received: March 24, 2014; Accepted; April 3, 2014

Abstract: The objective of this study was to investigate the osmotic dehydration of Oyster mushrooms in salt-sugar solution at different solution concentrations, immersion times, temperatures and solution to fruit ratio to analyze the water loss, solute gain and weight reduction. Salt-sugar uptake and water transfer were quantitatively investigated during osmotic dehydration of Oyster mushrooms using response surface methodology. Experiments were conducted in a thermostatically controlled agitating incubator. With respect to water loss, solute gain and weight reduction both linear and quadratic effects of four process variables were found to be significant. For each response, second order polynomial models were developed using multiple linear regression analysis. ANOVA was performed to check the adequacy and accuracy of the fitted models. The response surfaces and contour maps showing the interaction of process variables were constructed. Applying desirability function method, the optimum operating conditions were found to be: solution temperature $-42.3^{\circ} \mathrm{C}$, immersion time $-44.21 \mathrm{~min}$, salt-sugar concentration $15 \%: 52.57^{\circ} \mathrm{B}$ and solution to fruit ratio 4.99:1. At these optimum values, water loss, solute gain and weight reduction was $41,2.15$ and 38.6 ( $\mathrm{g} / 100 \mathrm{~g}$ initial mass) respectively.

Keywords: Mushrooms, Optimization, Osmotic dehydration, Response surface methodology, Salt-sugar solution

\section{INTRODUCTION}

Edible mushrooms are fleshy and spore-bearing fruiting body of endowed fungi (mostly Basidiomycetes) that grow naturally on the trunks, roots and above ground on soil or on its food source, which mainly comprises of dead matter or waste material (Chang and Miles, 1992; Stamets, 2001). The production and consumption of mushrooms is increasing tremendously throughout the world due to greater awareness of their nutritive and medicinal attributes. They have been consumed and appreciated for their flavour, economical and ecological values besides medicinal properties from ancient times (Ares et al., 2007).

The mushrooms are credited to be the third largest macro-fungus cultivated as food for industrial purposes worldwide. Pleurotus spp. are the second most cultivated edible mushrooms worldwide after Agaricus bisporus which constitute about $25 \%$ of total world production of cultivated mushrooms (Sanchez, 2010). Pleurotus sajor-caju popularly known as "Dhingri" in India is endowed with high protein content (rich in all the essential amino acids) required for an adult. Approximately 25-35\% of total amino acids occur as free amino acids. They are also known to be excellent sources of riboflavin, niacin and patothenic acid. The mineral content in fresh mushrooms is higher than is found in many fresh vegetables and fruits (Bano et al., 1981). P. sajor-caju has benefited with hypertensive effects through its active ingredients (Alam et al., 2008), and are also known to be useful decomposers of various agricultural wastes (Kuforiji and Fasidi, 2008). In-vivo studies also revealed that diet from Oyster mushroom effectively retarded the progression of hypercholesterolemia and accumulation of cholesterol in liver (Bobek et al., 1997). However, shelf-life of fresh mushrooms is very limited and starts deteriorating soon after the harvest. This quick deterioration is mainly caused by high metabolic activity, respiration rate, dehydration, microbial and enzymatic activities (Ares et al., 2007). So, to explore the health benefits from mushrooms, there is necessity of post-harvest preservation like drying and dehydration.

Osmotic dehydration is a water removal process involving soaking foods, mostly fruits and vegetables in a hypertonic solution. Two major simultaneous counter-current flows occur during osmotic dehydration process; water flow out of the food into the solution and a simultaneous transfer of solute from the solution into the food (Madamba, 2003). Osmotic dehydration improves the sensorial and nutritional properties, preserve and improve the organoleptic properties of foods. Osmotic dehydration results in increased shelf-life. It is regarded as complementary treatment in food preservation technique in the processing of dehydrated foods, as it presents some of the benefits such as reducing the damage of heat to the flavour, colour as well as inhibits the browning by enzymes and reduces the energy costs compare to 
other heat processing techniques (Torres et al., 2006). Limited efforts have so far been made to process $P$. sajorcaju mushroom into dehydrated product. No attempt has been made to optimize the osmotic process parameters for osmo-cum-microwave dehydrated product of $P$. sajorcaju mushroom. The aim of the present study was to determine the effect of osmotic process parameters viz; solution temperature, salt-sugar concentration, duration of osmosis and solution to fruit ratio on water loss, solute gain and weight reduction and to optimize these parameters for developing higher quality finished dehydrated mushroom flakes.

\section{MATERIALS AND METHODS}

Experimental design and statistical analysis: Box-Behnken Design was used to design the experiments. The Response surface methodology (RSM) was applied to the experimental data using a commercial statistical package, Design-Expert trail version 8.0.7.1 (Statease Inc., Minneapolis, USA). RSM is an empirical statistical modeling technique employed for multiple regression analysis using quantitative data obtained from properly designed experiments to solve multivariate equations simultaneously (Prakash maran et al., 2013). The process parameters (independent variables) selected for the optimization were immersion time $\left(\beta_{1}\right)$, osmotic solution concentration (salt-sugar) $\left(\beta_{2}\right)$, osmotic solution temperature $\left(\beta_{3}\right)$ and solution to fruit ratio $\left(\beta_{4}\right)$. The range of each independent variable was; $\beta_{1}$ : 15-240 min, $\beta_{2}$ : $15 \%: 45-65^{\circ} \mathrm{B}, \beta_{3}: 30-60^{\circ} \mathrm{C}$ and $\beta_{4}$ : $4: 1-8: 1$. The effects of the variables were studied on water loss (WL), solute gain (SG) and weight reduction (WR) of the slices during osmotic process. The variables were standardized for ease in computation and to reduce their relative effect on the responses. The number of experiments $(\mathrm{N})$ required for the development of Box-Behnken Design is defined as $\mathrm{N}=2 \mathrm{k}(\mathrm{k}-1)+\mathrm{C}_{\mathrm{o}}$ (where $\mathrm{k}$ is number of factors and $\mathrm{C}_{\mathrm{o}}$ is the number of central point). The design included 29 experiments with 5 central points. The following polynomial model was fitted to the data:

$$
\begin{aligned}
\mathbf{Y}= & b_{0}+b_{1} \beta_{1}+b_{2} \beta_{2}+b_{3} \beta_{3}+b_{4} \beta_{4}+b_{12} \beta_{12}+b_{13} \beta_{13}+ \\
& b_{14} \beta_{14}+b_{23} \beta_{23}+b_{24} \beta_{24}+b_{34} \beta_{34}+b_{11} \beta_{1}{ }^{2}+b_{22} \\
& \beta_{2}{ }^{2}+b_{33} \beta_{3}{ }^{2}+b_{44} \beta_{4}{ }^{2}
\end{aligned}
$$

Where, $b_{n}$ are constant regression coefficients; $\mathrm{Y}$ is the response (i.e. WL, SG and WR); $\beta_{1}, \beta_{2}, \beta_{3}$ and $\beta_{4}$ are immersion time, salt-sugar concentration, temperature and STFR respectively. Statistical significance of the terms in the regression equations was examined. Response surface plots were generated with the same software.

Raw materials: Oyster mushrooms ( $P$. sajor-caju) were used for the experimental studies. Fully matured mushrooms of commercial grade were procured from Mushroom Research Farm, Punjab Agricultural University, Ludhiana, India. The average moisture content of the mushrooms was found to be $90.3 \%$ on a wet basis initially. The mushrooms were cut into slices and were pre-treated using anti-microbial agent (Citric acid @ 40g/l) to avoid enzymatic browning (Brennan and Gormely, 2000). The commercial TATA salt and sugar was purchased from a local supermarket and were considered as an osmotic agents for osmotic study, for being cheap and easy availability.

Experimental procedure: The osmotic dehydration study was conducted in glass beakers, which were placed in a thermostatically controlled shaking incubator. For each experiment, known weights of mushroom was taken in a glass beakers containing calculated volumes of osmotic solution (STFR) of different salt-sugar concentrations and were placed inside a temperature and agitation controlled incubator. At each sampling time ranging from 15-240 min, the mushroom slices were taken out and then gently blotted with soft adsorbent paper and weighed and the effect of temperature was investigated. In each of the experiments fresh osmotic salt-sugar syrup was used. All the experiments were done in duplicates and the average value was taken for calculations. Agitation was necessary to improve the mass transfer to maintain uniform concentration, temperature profile and to prevent the formation of a dilute solution film around the samples. For each experiment a constant agitation speed of $150 \mathrm{rpm}$ was maintained. Analysis for each sample was carried out; from which WL, SG and WR data were obtained. Net loss of water and solute gain after osmotic dehydration was calculated using the relationship:
$\mathbf{W L}=\mathrm{WR}+\mathrm{SG}$
SG $=\left(\mathrm{m}-\mathrm{m}_{\mathrm{o}}\right) / \mathrm{M}_{\mathrm{o}}$
$\mathbf{W R}=\left(\mathrm{M}_{\mathrm{o}}-\mathrm{M}\right) / \mathrm{M}_{\mathrm{o}}$

Where, $\mathrm{M}_{0}$ - initial mass of sample $(\mathrm{g}), \mathrm{M}$ - mass of sample after dehydration $(\mathrm{g}), \mathrm{m}_{0}$ - initial mass of the solids in sample $(\mathrm{g}), \mathrm{m}$ - mass of the solids in sample after dehydration $(\mathrm{g})$

\section{RESULTS AND DISCUSSION}

RSM modeling and effect of process variables on responses: According to the Box-Behnken Design, experiments were performed in order to find out the optimum combination of process parameters and to study their effects on WL, SG and WR for the osmotic dehydration of mushrooms. A model 'F-value' denotes 'F-statistic' and is the ratio of treatment mean sum of squares to the error mean sum of squares. F-value should be always higher as it represents the significance of the model. Lesser the value of F-value, it represents least significant/non-significant or more error in the model. F-value and p-value are inter-related. From the table values of process variables, it can be noticed that as F-value increases p-value decreases, hence represents more significance. A Model F-value of 11.507, 26.668 and 8.199 for WL, SG and WR respectively implies that the model is significant $(\mathrm{P}<0.01)$. The 'lack of Fit F-value' of 1.612, 0.323 and 1.476 for WL, SG and WR was not 
Table 1. ANOVA for water loss during osmotic dehydration of Oyster mushroom.

\begin{tabular}{lcccc}
\hline & & \multicolumn{3}{c}{ Water loss } \\
\cline { 3 - 5 } Source & $\mathbf{R}^{2}$ & $\begin{array}{c}\text { Sum of } \\
\text { squares }\end{array}$ & F-value & p-value \\
\hline Model & 43.588 & 451.179 & 11.507 & $<0.0001$ \\
$\beta_{1}$ - Immersion & 2.035 & 49.714 & 17.751 & 0.001 \\
time & & 3.396 & 1.212 & 0.289 \\
$\beta_{2}$ - Salt-Sugar & 0.532 & 3.39 .473 & 117.640 & 0.0001 \\
$\beta_{3}$-Temp. & 5.240 & 3.901 & 0.679 & 0.424 \\
$\beta_{4}$-STFR & 0.398 & 1.907 & 0.0795 \\
$\beta_{12}$ & -0.222 & 0.197 & 0.070 & 0.795 \\
$\beta_{13}$ & 0.192 & 0.147 & 0.052 & 0.822 \\
$\beta_{14}$ & 0.077 & 0.024 & 0.008 & 0.928 \\
$\beta_{23}$ & 0.069 & 0.019 & 0.007 & 0.936 \\
$\beta_{24}$ & 0.206 & 0.169 & 0.060 & 0.809 \\
$\beta_{34}$ & 0.021 & 0.002 & 0.001 & 0.980 \\
$\beta_{1}{ }^{2}$ & -1.739 & 19.611 & 7.002 & 0.019 \\
$\beta_{2}{ }^{2}$ & -0.376 & 0.916 & 0.327 & 0.577 \\
$\beta_{3}{ }^{2}$ & -2.903 & 54.669 & 19.520 & 0.001 \\
$\beta_{4}{ }^{2}$ & -0.304 & 0.599 & 0.214 & 0.651 \\
Lack of Fit & & 1.612 & & \\
$\mathrm{R}^{2}$ & & 0.92 & & \\
Adj. ${ }^{2}$ & & 0.84 & & \\
Pred. ${ }^{2}$ & & 0.861 & & \\
CV $(\%)$ & & 4.044 & & \\
Adeq Precision & & 12.089 & & \\
\hline
\end{tabular}

significant which indicated that the model was adequate for predicting the response.

Moreover the predicted $\mathrm{R}^{2}$ values for WL, SG and WR of $0.861,0.84$ and 0.813 were in reasonable agreement with adjusted $\mathrm{R}^{2}$ of $0.84,0.927$ and 0.782 . The independent process parameters $\beta_{1}, \beta_{2}, \beta_{3}$ and $\beta_{4}$ were optimized for maximum WL and minimum SG. An analysis of variance was conducted to determine the significant effects of process variables on each response. Tables 1, 2 and 3 show that all the process variables were statistically significant for WL, SG and WR ( $p<0.05)$. Coefficient of determination $\mathrm{R}^{2}$ and adj $-\mathrm{R}^{2}$ were calculated to check the adequacy and fitness of the model. The adjusted $\mathrm{R}^{2}$ value corrects the $\mathrm{R}^{2}$ value for the sample size and for the number of terms in the model. The values of $\mathrm{R}^{2}$ were calculated to be $0.92,0.964$ and 0.891 for WL, SG and WR respectively which signifies the compatibility of the experimental data. The $\mathrm{R}^{2}$ value was always between 0 and 1 , and a value $>0.75$ indicated aptness of the model. For a good statistical model, $\mathrm{R}^{2}$ value should be close to 1.0 . These higher values also signify the high significance of the model. If there are many terms in the model and the sample size is not very large, the adjusted $\mathrm{R}^{2}$ may be noticeably smaller than the $\mathrm{R}^{2}$. Here in this case also, it can be noticed adjusted $R^{2}$ value are lesser than the $R^{2}$. The closer values of $R^{2}$ and adj. $\mathrm{R}^{2}$ obtained in the study explicates that the predicted values are in good agreement with the experimental values.

Higher values of coefficient of determination obtained for response variables indicated that the developed
Table 2. ANOVA for solute gain during osmotic dehydration of Oyster mushroom.

\begin{tabular}{|c|c|c|c|c|}
\hline \multirow[b]{2}{*}{ Source } & \multirow[b]{2}{*}{$\mathbf{R}^{2}$} & \multicolumn{3}{|c|}{ Solute gain } \\
\hline & & $\begin{array}{c}\text { Sum of } \\
\text { squares }\end{array}$ & F-value & p-value \\
\hline Model & 2.724 & 12.624 & 26.668 & $<0.0001$ \\
\hline $\begin{array}{l}\beta_{1} \text { - Immersion } \\
\text { time }\end{array}$ & 0.448 & 2.410 & 71.272 & $<0.0001$ \\
\hline$\beta_{2}$ - Salt-Sugar & 0.320 & 1.228 & 36.312 & $<0.0001$ \\
\hline$\beta_{3}$-Temp. & 0.746 & 6.672 & 197.325 & $<0.0001$ \\
\hline$\beta_{4}-\mathrm{STFR}$ & 0.262 & 0.821 & 24.280 & 0.0002 \\
\hline$\beta_{12}$ & -0.005 & 0.000 & 0.003 & 0.959 \\
\hline$\beta_{13}$ & -0.192 & 0.147 & 4.339 & 0.056 \\
\hline$\beta_{14}$ & 0.007 & 0.000 & 0.005 & 0.944 \\
\hline$\beta_{23}$ & 0.025 & 0.003 & 0.075 & 0.788 \\
\hline$\beta_{24}$ & 0.026 & 0.003 & 0.082 & 0.779 \\
\hline$\beta_{34}$ & 0.077 & 0.024 & 0.700 & 0.417 \\
\hline$\beta_{1}^{2}$ & 0.042 & 0.011 & 0.335 & 0.572 \\
\hline$\beta_{2}^{2}$ & 0.119 & 0.092 & 2.720 & 0.121 \\
\hline$\beta_{3}{ }^{2}$ & -0.393 & 0.999 & 29.555 & $<0.0001$ \\
\hline$\beta_{4}^{2}$ & 0.017 & 0.002 & 0.053 & 0.822 \\
\hline Lack of Fit & & 0.323 & & \\
\hline $\mathrm{R}^{2}$ & & 0.964 & & \\
\hline Adj. $R^{2}$ & & 0.927 & & \\
\hline Pred. $\mathrm{R}^{2}$ & & 0.84 & & \\
\hline $\mathrm{CV}(\%)$ & & 6.979 & & \\
\hline Adeq Precision & & 20.114 & & \\
\hline
\end{tabular}

model for WL, SG and WR accounted for and adequately explained $92,96.4$ and 89.1 percent of the total variation. The coefficient of variation $(\mathrm{CV} \%)$ indicates the relative dispersion of the experimental points from the predictions of the second-order polynomial models (Prakash maran et al., 2013). The values of CV are low as 4.044, 6.979 and 4.39 for WL, SG and WR, which indicate that the deviations between experimental and predicted values are low. The values of Adeq Precision are 12.089, 20.114 and 9.943 for WL, SG and WR. Adeq Precision measures the signal to noise ratio. A ratio greater than 4 is desirable. In this work, the ratio is found to be $>9$ which indicates an adequate signal. The comparative effect of each factor on WL, SG and WR was observed by the F-values in the ANOVA (Tables 1-3) and also by the magnitudes of coefficients of the coded variables. The F-values indicated that solution temperature and immersion time were the most influencing factors followed by salt-sugar concentration and STFR was least effective over WL, SG and WR.

It was reported that above $60 \%$ sugar concentration, additional increase in sugar concentration did not promote further water loss in fruits and vegetables (Ponting et al., 1966). Therefore, $65 \%$ sugar was chosen as the upper limit for the salt-sugar concentration in this study. The effect of $\beta_{1}, \beta_{2}, \beta_{3}$ and $\beta_{4}$ on the $\mathrm{WL}$ is given in fig. 1 . The WL is increased with temperature especially in the early stages of the immersion, after which the rate of WL from mushrooms into the solution gradually slowed down 
Table 3. ANOVA for weight reduction during osmotic dehydration of Oyster mushroom.

\begin{tabular}{|c|c|c|c|c|}
\hline \multirow[b]{2}{*}{ Source } & \multirow[b]{2}{*}{$\mathbf{R}^{2}$} & \multicolumn{3}{|c|}{ Weight reduction } \\
\hline & & $\begin{array}{l}\text { Sum of } \\
\text { squares }\end{array}$ & F-value & p-value \\
\hline Model & 41.065 & 332.099 & 8.199 & 0.0002 \\
\hline $\begin{array}{l}\beta_{1} \text { - Immersion } \\
\text { time }\end{array}$ & 1.587 & 30.233 & 10.450 & 0.006 \\
\hline$\beta_{2^{-}}$Salt-Sugar & 0.212 & 0.540 & 0.187 & 0.672 \\
\hline$\beta_{3}$-Temperature & 4.494 & 242.374 & 83.778 & $<0.0001$ \\
\hline$\beta_{4}$-STFR & 0.137 & 0.224 & 0.077 & 0.785 \\
\hline$\beta_{12}$ & -0.217 & 0.188 & 0.065 & 0.802 \\
\hline$\beta_{13}$ & 0.383 & 0.587 & 0.203 & 0.659 \\
\hline$\beta_{14}$ & 0.070 & 0.020 & 0.007 & 0.935 \\
\hline$\beta_{23}$ & 0.043 & 0.008 & 0.003 & 0.960 \\
\hline$\beta_{24}$ & 0.179 & 0.129 & 0.044 & 0.836 \\
\hline$\beta_{34}$ & -0.056 & 0.012 & 0.004 & 0.949 \\
\hline$\beta_{1}^{2}$ & -1.881 & 22.940 & 7.929 & 0.014 \\
\hline$\beta_{2}^{2}$ & -0.595 & 2.295 & 0.793 & 0.388 \\
\hline$\beta_{3}{ }^{2}$ & -2.611 & 44.208 & 15.281 & 0.002 \\
\hline$\beta_{4}^{2}$ & -0.421 & 1.147 & 0.397 & 0.539 \\
\hline Lack of Fit & & 1.476 & & \\
\hline $\mathrm{R}^{2}$ & & 0.891 & & \\
\hline Adj. $\mathrm{R}^{2}$ & & 0.782 & & \\
\hline Pred. $\mathrm{R}^{2}$ & & 0.813 & & \\
\hline $\mathrm{CV}(\%)$ & & 4.39 & & \\
\hline Adeq Precision & & 9.943 & & \\
\hline
\end{tabular}

with time towards equilibrium end point. On the other hand, the WL increased gradually with salt-sugar concentration over the entire osmotic dehydration process. Higher temperatures seem to promote faster water loss through swelling and plasticising of cell membranes as well as the better water transfer characteristics on the product surface due to lower viscosity of the osmotic medium (Contreras and Smyral, 1981). Rapid removal of water in early stages with increasing temperatures of osmosis has been reported for mushrooms (Kar and Gupta, 2001; Murumkar et al., 2007), green pumpkins (Chang et al., 2003), potatoes (Eren and Kaymak-Ertekin, 2006), litchi (Vishal et al., 2009) and papaya (Jain et al., 2011). So, initial stages of osmotic dehydration is the most important one, since the transport phenomena are faster and they have a dramatic impact on further evolution of the osmotic process (Hawkes and Flink, 1978; Conway et al., 1983; Biswal et al., 1991 ). The effect of $\beta_{1}, \beta_{2}, \beta_{3}$ and $\beta_{4}$ on the SG is given in fig.2. The SG increases sharply with immersion time and temperature. This can be attributed to the increased mass transfer of sugar molecules due to possible membrane swelling or plasticizing effect which might increase the cell membrane permeability to sucrose molecules (Lazerides et al., 1997). The effect of $\beta_{1}, \beta_{2}, \beta_{3}$ and $\beta_{4}$ on the WR is given in fig. 3. WR mainly depends upon WL and SG during osmotic dehydration process.

An empirical model for the best response was obtained through RSM. The mathematical expressions of

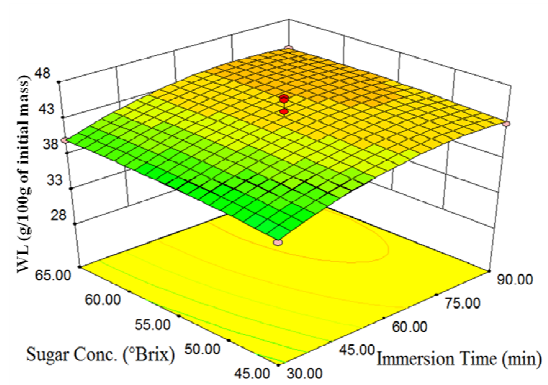

(a)

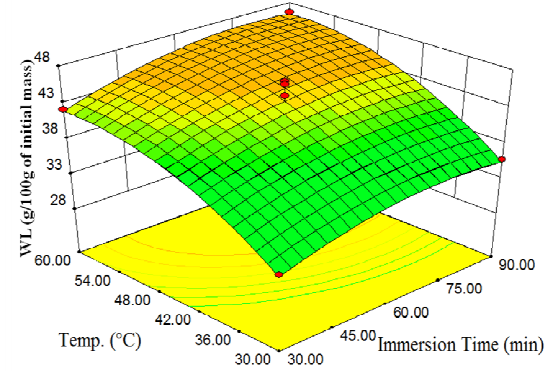

(b)

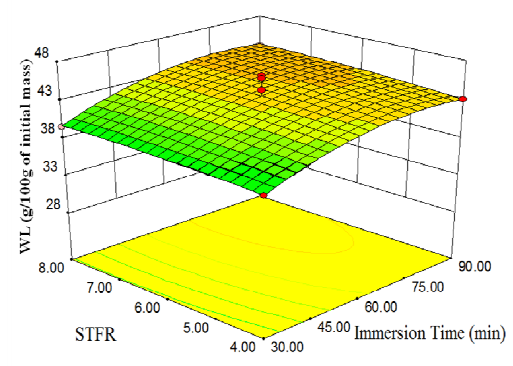

(c)

Fig. 1. WL during osmotic dehydration of mushroom as a function of : (a) sugar concentration and immersion time (b) solution temperature and immersion time (c) STFR and immersion time.

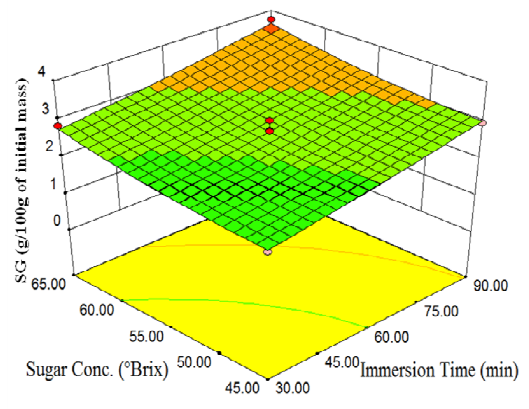

(a)

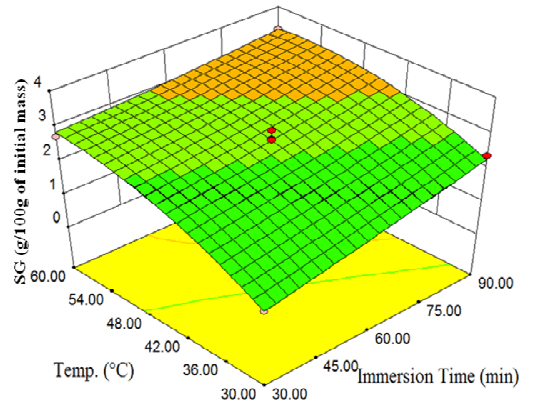

(b)

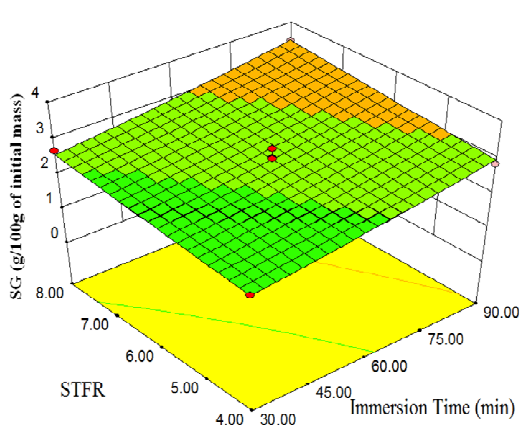

(c)

Fig. 2. SG during osmotic dehydration of mushroom as a function of: (a) sugar concentration and immersion time (b) solution temperature and immersion time (c) STFR and immersion time. 


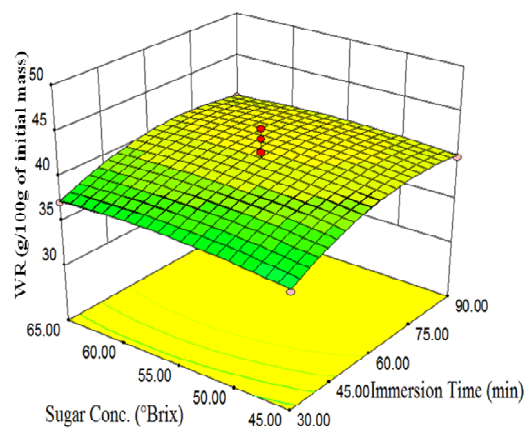

(a)

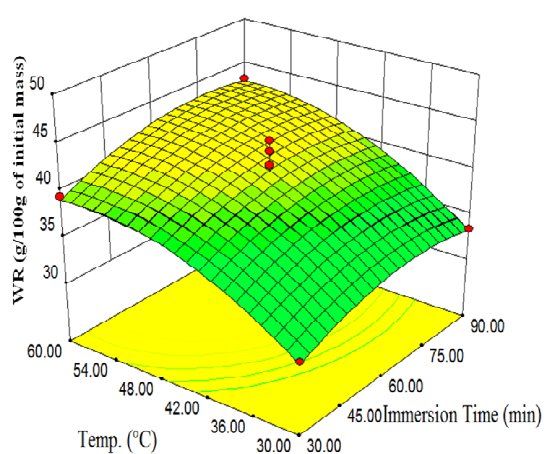

(b)

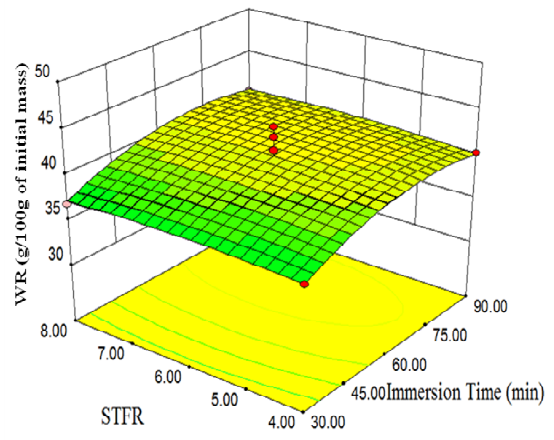

(c)

Fig. 3. WR during osmotic dehydration of mushroom as a function of: (a) sugar concentration and immersion time (b) solution temperature and immersion time (c) STFR and immersion time.

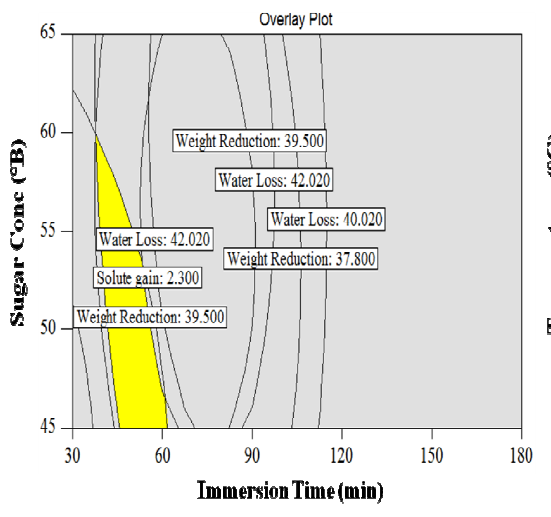

(a)

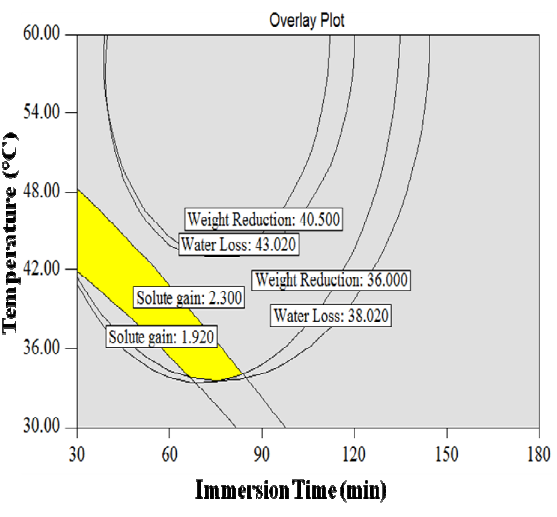

(b)

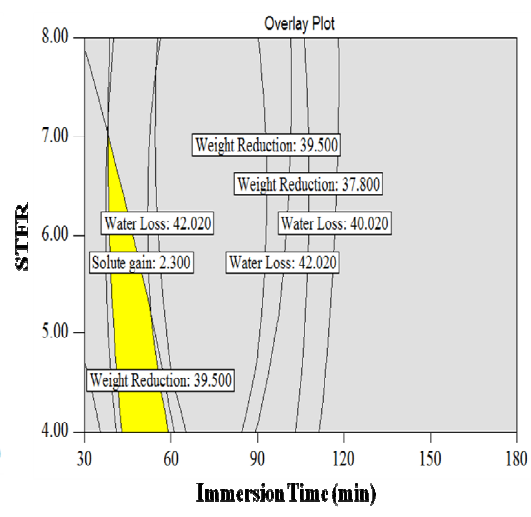

(c)

Fig. 4. Superimposed contour plots of different responses for optimization of osmotic dehydration of mushroom as function of: (a) sugar concentration and immersion time (b) solution temperature and immersion time (c) STFR and immersion time.

relationship describing the effects of process variables to the response are shown below:

$\mathbf{W L}=43.59+2.04 \beta_{1}+0.53 \beta_{2}+5.24 \beta_{3}+0.40 \beta_{4}-0.22$

$$
\beta_{12}+0.19 \beta_{13}+0.077 \beta_{14}+0.069 \beta_{23}+0.21 \beta_{24}+0.021
$$$$
\beta_{34}-1.74 \beta_{1}{ }^{2}-0.38 \beta_{2}{ }^{2}-2.90 \beta_{3}{ }^{2}-0.30 \beta_{4}{ }^{2}
$$

$\mathbf{S G}=2.72+0.45 \beta_{1}+0.32 \beta_{2}+0.75 \beta_{3}+0.26 \beta_{4}-4.866 \mathrm{E}$ $-003 \beta_{12}-0.19 \beta_{13}+6.598 \mathrm{E}-003 \beta_{14}+0.025 \beta_{23}$ $+0.026 \beta_{24}+0.077 \beta_{34}+0.042 \beta_{1}{ }^{2}+0.12 \beta_{2}{ }^{2}-0.39$ $\beta_{3}{ }^{2}+0.017 \beta_{4}{ }^{2}$

$\mathbf{W R}=41.06+1.59 \beta_{1}+0.21 \beta_{2}+4.49 \beta_{3}+0.14 \beta_{4}-0.22$ $\beta_{12}+0.38 \beta_{13}+0.070 \beta_{14}+0.043 \beta_{23}+0.18 \beta_{24^{-}}$ $0.056 \beta_{34}-1.88 \beta_{1}^{2}-0.59 \beta_{2}^{2}-2.61 \beta_{3}^{2}-0.42 \beta_{4}{ }^{2}$

Where, WL, SG, WR are water loss, solute gain and weight reduction respectively, and $\beta_{1}, \beta_{2}, \beta_{3}$ and $\beta_{4}$ are the coded values of the test variables, immersion time, salt-sugar concentration, solution temperature and solution to fruit ratio respectively, as mentioned earlier.

The presence of positive interaction terms between $\beta_{1}$, $\beta_{2}, \beta_{3}$ and $\beta_{4}$ indicated that increase in their levels increased WL, SG and WR. The negative values of quadratic terms of process variables of osmosis indicated that higher values of these variables further reduced WL, SG and WR. The analysis of variance of quadratic regression model demonstrated that equation 5, 6 and 7 were highly significant models, as were evident from F-test with very low probability value ( $\mathrm{p}$ model $=<0.0001,<0.0001$ and 0.0002 for WL, SG and WR respectively. This indicates that the linear terms of $\beta_{1}, \beta_{2}, \beta_{3}$ and $\beta_{4}$ of osmosis were highly significant at 5 percent level.

Response surface and contour plots: Response surface plots as a function of two factors at a time, maintaining all other factors at fixed levels are more helpful in understanding both the main and the interactive effects of these two factors. The response surface curves were plotted to understand the interaction of the variables and to determine the optimum level of each variable for maximum response. The $3 \mathrm{D}$ surface and contour plots for WL, SG and WR along with overlay plots are shown in figs. 1-4 respectively. Figures show the effects of process variables such as $\beta_{1}, \beta_{2}, \beta_{3}$ and $\beta_{4}$ on WL, SG and WR during the osmotic dehydration of Oyster mushrooms. The higher processing temperature and immersion time promote rapid water loss and solute uptake along with increased salt-sugar concentration and STFR. Temperature has an effect on the cell membrane permeability that could allow solute to enter by losing its selectivity. Decrease of solution viscosity at higher temperature may influence salt gain due to fact that lower viscosity decreases the resistance to diffusion of solutes into the sample tissue. Increased 
Table 4. Range of process parameters and their importance for optimization of osmotic dehydration and solution generated through the RSM Technique in salt-sugar solution.

\begin{tabular}{lcccc}
\hline Process parameters & Goal & $\begin{array}{c}\text { Experimental } \\
\text { range }\end{array}$ & $\begin{array}{c}\text { Importance } \\
\text { Optimum } \\
\text { values }\end{array}$ & Desirability \\
\hline Time $(\mathrm{min})$ & is in range & $30-90$ & 3 & 44.21 \\
Salt $(\%)$ : Sugar $\left({ }^{\circ} \mathrm{B}\right)$ & is in range & $15: 45-65$ & 3 & $15: 52.57$ \\
Temp $\left({ }^{\circ} \mathrm{C}\right)$ & target & 36 & 3 & 42.30 \\
STFR & is in range & $4: 1-8: 1$ & 3 & $4.99: 1$ \\
Responses & & & & Predicted \\
values & 0.660 \\
WL $(\mathrm{g} / 100 \mathrm{~g}$ of initial mass) & maximize & $32.16-46.64$ & 3 & 41 \\
SG $(\mathrm{g} / 100 \mathrm{~g}$ of initial mass) & minimize & $0.984-3.74$ & 3 & 2.14823 \\
WR $(\mathrm{g} / 100 \mathrm{~g}$ of initial mass) & maximize & $31.18-44.21$ & 3 & 38.599 \\
\hline
\end{tabular}

concentration of the salt solution also led to increase in salt gain. This is probably due to an increase of osmotic pressure gradient and consequent loss of functionality of cell plasmatic membrane that allows solute to enter.

Rapid loss of water and uptake of solute near the surface in the beginning may result in structural changes leading to crust formation/compaction of surface layers and which results in increased mass transfer resistance for water and solutes (Alam et al., 2010). During osmotic dehydration, water removal from the product is always accompanied by the simultaneous counter diffusion of solutes from the osmotic solution into the tissue. In most common operating conditions, mass transfer mainly occurs during the first $2 \mathrm{~h}$ for water loss and first $50 \mathrm{~min}$ for solute gains (Rault et al., 1989). Further, Rezagah et al. (2010) confessed that moisture loss occurs in the first hour of the osmotic process. The mass transfer rates thus become progressively lower with time and water loss stops, whereas solute gain goes on increasing regularly (Ertekin and Çakaloz, 1995). Rapid removal of water in the early stages of osmotic dehydration has been reported by several authors (Lazarides et al., 1995; Ertekin and Çakaloz, 1996; Shi and Le Maguer, 2002). Moreover, mixture of sugar and salt solutions in osmotic dehydration process proved the best choice based on effectiveness, convenience and flavour (Dehkordi, 2010; Manafi et al., 2010).

Optimization of osmotic dehydration of mushroom: Design-Expert trail version 8.0.7.1 (Statease Inc., Minneapolis, USA) was used for getting optimal values for multiple responses, as discussed earlier. Graphical multi-response optimization technique was adopted to determine the workable optimum conditions for the osmotic dehydration of Oyster mushrooms. The contour plots for all the responses were superimposed and regions that best satisfy all the constraints were selected as optimum conditions. The main criteria for constraints optimization were maximum possible water loss, weight reduction and minimum solute gain.

These constraints resulted in feasible zone (yellow coloured area in the superimposed contour plots) of the optimum conditions. Superimposed contour plots having common superimposed area of all the responses for osmotic dehydration in salt-sugar solution are presented in figs. 1-4. These results clearly indicated the suitability of the developed models.

The optimum range of process parameters obtained for osmotic dehydration of Oyster mushrooms were: $30-90$ min immersion time; $15 \%: 45-65^{\circ} \mathrm{B}$ salt: sugar concentration; $36^{\circ} \mathrm{C}$ and 4:1-8:1 solution to fruit ratio. Numerical multi response technique was carried out for optimization of process. Equal importance of ' 3 ' was given to all the four parameters. The constraints were set such that the selected variables would be minimum from economical point of view for the most important product attribute. Goal of the present study was to maximize the water loss and weight reduction values as high as possible and to minimize solute as low as possible. The optimum conditions were found to be $\beta_{1}=44.21 \mathrm{~min}, \beta_{2}=15 \%: 52.57^{\circ} \mathrm{B}, \beta_{3}=42.30^{\circ} \mathrm{C}$ and $\beta_{4}=4.99: 1$. At these optimum conditions, WL, SG and WR were found to be $41,2.15$ and $38.6(\mathrm{~g} / 100 \mathrm{~g}$ of initial mass) with overall desirability value of 0.660 . Table 4 shows the software generated optimum conditions i.e. range of process parameters and their importance for optimization of osmotic dehydration and solution generated through the RSM Technique in salt-sugar solution.

\section{Conclusion}

Mass exchange evaluation during optimization of osmotic dehydration for Oyster mushrooms in salt-sugar solution was carried out to increase process efficiency of osmotic dehydration process, so that this technique could be beneficially practiced in larger food industries. Analysis of variance showed that the effects of all the process variables including solution temperature, immersion time, salt concentrations and STFR were statistically significant. Second order polynomial models were obtained for predicting water loss, solute gain and weight reduction. The optimal conditions for maximum water loss and weight reduction and minimum solute gain corresponded to immersion time $44.21 \mathrm{~min}$, sucrose concentration of $52.57 \%$, solution temperature $42.3^{\circ} \mathrm{C}$ and STFR 4.99:1 was $41(\mathrm{~g} / 100 \mathrm{~g}$ of initial mass), weight reduction of $38.6(\mathrm{~g} / 100 \mathrm{~g}$ of initial mass) and solute 
gain 2.15 (g/100 $\mathrm{g}$ of initial mass) respectively. However, quality characteristics such as colour, taste, texture, shrinkage and rehydration effects should also be investigated to achieve the desired final product specifications for commercial processing.

\section{ACKNOWLEDGEMENT}

The author would wish to thank "The Ministry of Science and Technology, Department of Science and Technology (DST), GOI" for providing financial support during the course of Research Studies.

\section{REFERENCES}

Alam, M. S., Singh, A. and Sawhney, B. K. (2010). Response Surface Optimization of Osmotic Dehydration Process for Anola Slices. Food Science and Technology, 47: 47- 54

Alam, N., Amin, R., Khan, A., Ara, I. Shim, M. J., Lee, M. W. and Lee, T. S. (2008). Nutritional analysis of cultivated mushrooms in Bangladesh - Pleurotus ostreatus, Pleurotus sajor-caju, Pleurotus florida and Calocybe indica. Mycobiology, 36: 228- 232.

Ares, G., Lareo, C. and Lema, P. (2007). Modified atmospheric packaging for post harvest storage of mushrooms. A review. Fresh Produce Journal, 1:3240.

Bano, Z., Bhagya, S. and Srinivasan, K. S. (1981). Essential amino acid composition and proximate analysis if mushrooms Pleurotuseous and P. florida. Mushroom Newsletter for the Tropics, 1:3-6.

Biswal, R. N., Bozorgmehr, K., Tompkins, F. D. and Liu, X. (1991). Osmotic concentration of green beans prior to freezing. Journal of Food Science, 56:1008-1012.

Bobek, P., Ozdín, L. and Kuniak, L. (1997). Effect of oyster mushroom and isolated $\beta$-glucan on lipid peroxidation and on the activities of antioxidative enzymes in rats fed the cholesterol diet. The Journal of Nutritional Biochemistry, 8: 469- 471.

Brennan, M. H. and Gormely (2000). Extending the shelf life of fresh sliced mushrooms. Journal of the Science of Food and Agriculture, 26: 401-411.

Chang, M. J., Han, M. R. and Kim, M. H. (2003). Effects of salt addition in sugar based Osmotic dehydration on mass transfer and browning reaction of green Pumpkin. Agriculyural Chemistry and Biotechnology, 46: 92- 96.

Chang, S. T. and Miles, P. G. (1992). Mushroom biology: A new discipline. The Mycologist, 6:64-65.

Contreras, J. E. and Smyral, T. G. (1981). An evaluation of osmotic concentration of apple rings using corn syrup solids solutions. Canadian Institute of Food Science and Technology Journal, 14:310-314.

Conway, J., Castaigne, F., Picard, G. and Vovan, X. (1983). Mass transfer considerations in the osmotic dehydration of apples. Canadian Institute of Food Science Technology Journal, 16: 25- 29.

Dehkordi, B. M. (2010). Optimization the process of osmo convective drying of edible button mushrooms using response surface methodology (RSM). World Academy of Science, Engineering and Technology, 62.

Eren, I. and Kaymak-Ertekin, F. (2006). Optimization of osmotic dehydration of potato using response surface methodology. Journal of Food Engineering, 79, 344352.

Ertekin, F. K. and Çakaloz, T. (1995). Osmotic dehydration of peas: II. Influence of osmosis on drying behaviour and product quality. Journal of Food Processing and
Preservation, 20:105-119.

Ertekin, F. K. and Çakaloz, T. (1996). Osmotic dehydration of peas: I. Influence of process variables on mass transfer. Journal of Food Processing and Preservation, 20:87- 104 .

Hawkes, J. and Flink, J. M. (1978). Osmotic concentration of fruit slices prior to freeze dehydration. Journal of Food Processing and Preservation, 2: 265-284.

Jain, S. K., Verma, R. C., Murdia, L. K., Jain, H. K. and Sharma, G. P. (2011). Optimization of Process Parameters for Osmotic Dehydration of Papaya Cubes. Food Science and Technology, 48: 211-217.

Kar, A. and Gupta, D. K. (2001). Osmotic Dehydration Characteristics of Button Mushroom. Food Science and Technology, 40: 23- 27.

Kuforiji, O. O. and Fasidi, I. O. (2008). Enzyme activities of Pleurotus tuber-regium (Fries) Singer, cultivated on selected agricultural wastes. Bioresource Technology, 99: 4275- 4278.

Lazarides, H. N., Katsanidis, E. and Nickolaidis, A. (1995). Mass transfer kinetics during osmotic preconcentration aiming at minimal solid uptake. Journal of Food Engineering, 25: 151- 166.

Lazerides, H. N., Gekas, V. and Mavroudis, N. (1997). Apparent mass diffusivities in fruit and vegetable tissues undergoing osmotic processing. Journal of Food Engineering, 31: 315-324.

Madamba, P. S. (2003). Thin layer drying models for osmotically predried young coconut. Drying Technology, 21: 1759- 1780.

Manafi, M., Hesari, J., Peighambardoust, H. and Khoyi, M. R. (2010). Osmotic dehydration of apricot using saltsucrose solutions. World Academy of Science, Engineering and Technology, 44:1098- 1101.

Murumkar, R. P., Jain, S. K., Pilaskar, P. S. and Verma, R. C. (2007). Osmo-fluid bed drying of white button mushroom. Bioved-An International Bi-Annual Journal of Life Science, 18: 47- 52.

Ponting, J. D., Watters, G. G., Forrey, R. R., Jackson, R. and Stanley, W. L. (1966). Osmotic dehydration of fruits. Food Technology, 20:125- 128.

Prakash Maran, J. P., Manikandan, S., Thirugnanasambandham, K., Vigna Nivetha, C. and Dinesh, R. (2013). Box -Behnken design based statistical modeling for ultrasoundassisted extraction of corn silk polysaccharide. Carbohydrate Polymers, 92: 604- 611.

Rault, A. L., Lafont, F., Rios, G. and Guilbert, S. (1989). Osmotic dehydration: study of mass transfer in terms of engineering properties. In A. S. Majumdar and $\mathrm{M}$. Roques (Eds.), Drying. NY: Hemisphere Publishing House. 89: 487- 495.

Rezagah, M. E., Kashaninejad, M., Mirzaei, H. and Khomeiri, M. (2010). Osmotic dehydration of button mushroom: Fickian diffusion in slab configuration. Latin American Applied Research, 40:23-26.

Sanchez, C. (2010). Cultivation of Pleurotus ostreatus and other edible mushrooms. Applied Microbiology and Biotechnology, 85: 1321-1337.

Shi, J. and Le Maguer, M. (2002). Osmotic dehydration of foods: mass transfer and modeling aspects. Food Reviews International, 18: 305- 335.

Stamets, P. (2001). Novel antivirals from mushrooms. Herbal Gram. 51: 24-27.

Torres, J. D., Talens, P. and Escriche, I. A. (2006). Chiralt Influence of process conditions on mechanical properties of osmotically dehydrated mango. Journal of Food Engineering, 74: 240-246.

Vishal, K., Gunjan, K. and Sharma, P. D. (2009). Effect of Osmo-convective drying on quality of Litchi. Agricultural Engineering, 46: 31- 35. 